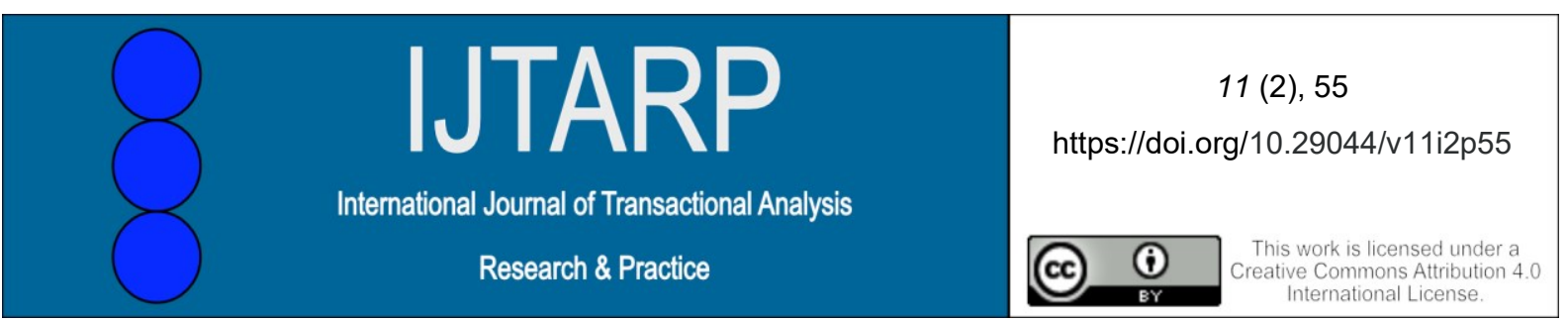

\title{
Graham Barnes - An Obituary - August 2020
}

Julie Hay

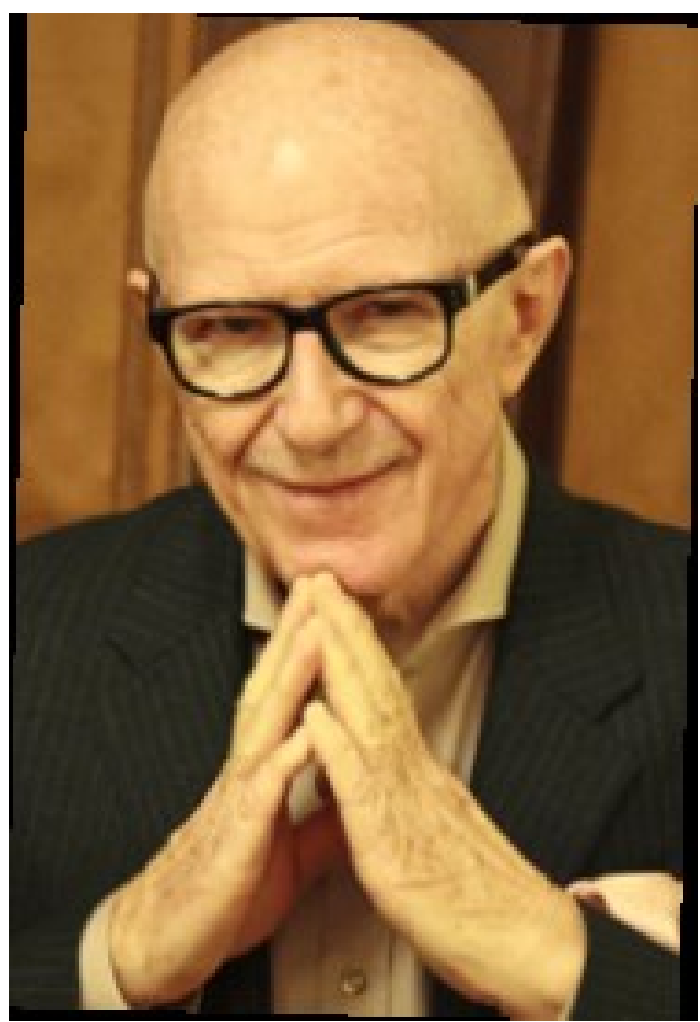

Graham Barnes

I was very sad to learn that Graham Barnes died from a heart attack on 9 August 2020 at his home in Stockholm, Sweden, at the age of 83. Graham contributed much to TA and he knew that I used his material extensively in my own teaching.

Graham was given the Eric Berne Memorial Award in 2005 for his article on 'Homosexuality in the First Three Decades of Transactional Analysis' (Barnes, 2004).

He was also one of the trainers in Raleigh, USA who contributed to the Social Action TA 101 project that ITAA and USATAA were offering free access to - see https://www.usataa.org/circles-of-interest/socialjustice-circle/project-ta-101/
Those who are familiar with my material will know that I quote extensively from his 1977 book TA after Eric Berne, as well as using his ideas about the drama diamond (Barnes, 1981). This is such a helpful way of understanding how life positions may show up as existential positions (attitudes) as Berne (1962) originally described them, or as behaviours, as Ernst (1971) showed, or as psychological level or emotional responses - which means that we may experience all three of the not-OK versions at the same time.

Having spent many years combating intolerance, Graham was very supportive when I challenged some TA colleagues about what I thought was an abusive way to apply TA theory to refugees. Because he was a 'famous' TA person, his support of me - and the refugees - was particularly powerful and welcomed.

His legacy will live on through his material within the TA community.

\section{References}

Barnes, G. (1977). (ed) Transactional Analysis after Eric Berne. New York: Harper's College Press.

Barnes, G. (1981). On Saying Hello: The Script Drama Diamond and Character Role Analysis. Transactional Analysis Journal, 11(1), 22-32.

https://doi.org/10.1177\%2F036215378101100105

Barnes, G. (2004). Homosexuality in the First Three Decades of Transactional Analysis' : A Study in the Theory and Practice of Transactional Analysis Psychotherapy. Transactional Analysis Journal, 34(2), 126-155. https://doi.org/10.1177/036215370403400205

Berne, E. (1962). Classification of positions. Transactional Analysis Bulletin, 1(3), 23.

Franklin H. Ernst Jr. (1971). The OK Corral: The Grid for Get-on-With, Transactional Analysis Journal, 1(4), 33-42. https://doi.org/10.1177/036215377100100409

Barnes, G. (1977). (Ed). Transactional Analysis after Eric Berne: Teachings and Practices of Three TA Schools. New York: Harper's College Press. 